Meta

Journal des tradlucteurs

Translators' Journal

\title{
Interpreting Between Greek Sign Language and Spoken Greek at the Aristotle University of Thessaloniki
}

\author{
Eleni Kassapi, Anastasia Efklides, Hariton M. Polatoglou, Maria Myronidou et \\ Maria Teresa Papaioannou
}

Volume 50, numéro 4, décembre 2005

Pour une traductologie proactive - Actes

For a Proactive Translatology — Proceedings

Por una traductología proactiva - Actas

URI : https://id.erudit.org/iderudit/019867ar

DOI : https://doi.org/10.7202/019867ar

Aller au sommaire du numéro

Éditeur(s)

Les Presses de l'Université de Montréal

ISSN

0026-0452 (imprimé)

1492-1421 (numérique)

Découvrir la revue

Citer cet article

Kassapi, E., Efklides, A., Polatoglou, H. M., Myronidou, M. \& Papaioannou, M. T. (2005). Interpreting Between Greek Sign Language and Spoken Greek at the Aristotle University of Thessaloniki. Meta, 50(4).

https://doi.org/10.7202/019867ar
Résumé de l'article

Notre projet pédagogique a pour but de renforcer l'appui continuel à la professionalisation de la communauté des interprètes de langue des signes à l'Université Aristote par l'organisation de cours de durée limitée sur l'interprétation de la langue des signes. La préparation des interprètes de la langue des signes est un projet expérimental patronné par le Social Policy Committee et réalisé en collaboration avec le Département de langue et littérature anglaises et le programme des études postuniversitaires de traduction et d'interprétation. Ce programme expérimental a été créé pour répondre aux besoins des étudiants sourds de l'université. 


\title{
Interpreting Between Greek Sign Language and Spoken Greek at the Aristotle University of Thessaloniki
}

\author{
ELENI KASSAPI \\ Aristotle University of Thessaloniki, Thessaloniki, Greece \\ kassapi@itl.auth.gr \\ ANASTASIA EFKLIDES \\ Aristotle University of Thessaloniki, Thessaloniki, Greece \\ Hariton M. Polatoglou \\ Aristotle University of Thessaloniki, Thessaloniki, Greece \\ MARIA MYRONIDOU \\ Aristotle University of Thessaloniki, Thessaloniki, Greece \\ MARIA TERESA PAPAIOANNOU \\ Aristotle University of Thessaloniki, Thessaloniki, Greece
}

\begin{abstract}
RÉSUMÉ
Notre projet pédagogique a pour but de renforcer l'appui continuel à la professionalisation de la communauté des interprètes de langue des signes à l'Université Aristote par l'organisation de cours de durée limitée sur l'interprétation de la langue des signes. La préparation des interprètes de la langue des signes est un projet expérimental patronné par le Social Policy Committee et réalisé en collaboration avec le Département de langue et littérature anglaises et le programme des études postuniversitaires de traduction et d'interprétation. Ce programme expérimental a été créé pour répondre aux besoins des étudiants sourds de l'université.
\end{abstract}

\begin{abstract}
This paper presents the first project on the formation of Sign Language Interpreters in Greek Universities. At the Aristotle University of Thessaloniki, the training of sign language interpreters is an experimental project organized by the Social Policy Committee and is carried out in collaboration with the School of English Studies and the Postgraduate Program in Translation and Interpretation Studies. This project has been initiated because of the realization that deaf students represent a linguistic minority in our University. In universities, the growing number of deaf students increases the demand for community and conference interpreting between the Greek sign language and the Greek - general or special - spoken language.
\end{abstract}

\section{MOTS-CLÉS/KEYWORDS}

Greek sign language, sign language interpretation, terminology, community interpretation, academic interpretation.

Sign interpretation in the universities ${ }^{1}$ is a growing sector (Harris, 1995). However, there are certain problems in supplying the required services at the Aristotle University of Thessaloniki. More specifically, there is not of a sufficient number of academically trained interpreters, specialized in scientific domains and thus proficient in verbalizing specialized scientific concepts. Greek sign language is a new language, not well studied as regards its syntax, morphology and lexicon, and relatively poor in conceptual sophistication. It is a developing language that needs to become the object of scientific study, which in turn will pave the way for the training of Greek sign language interpreters. 


\section{The Clientele}

Any eventual interpreting between signed and spoken Greek for academic purposes at the Aristotle University would have the following clientele: undergraduate deaf students in Visual \& Applied Arts, Education, Theology, Psychology, Law, Medicine, Architecture and Civil Engineering, Dentistry, Physical Education and Agriculture. This deduction is based on the following facts: loniki:

During the years 2000-2004, 25 deaf students enrolled at the Aristotle University of Thessa-

Faculty of Fine Arts: 4 (School of Cinema Studies: 2, School of Visual \& Applied Arts: 2);

Faculty of Philosophy: 5 (School of Psychology: 4, School of Philosophy and Education: 1);

School of Law: 4;

Faculty of Theology: 2;

Faculty of Health Sciences: 3;

Faculty of Engineering: 5;

Faculty of Physical Education: 1;

School of Agriculture: 1.

As observed above, deaf students tend to enter schools or faculties oriented towards applied sciences, mainly because of the professional opportunities they appear to offer and the limited need for abstract discourse.

\section{Interpreting Services and Interpreting Mediators}

Deaf students are faced with an objective communication problem, which prevents them from participating in the learning process. These students are evaluated every semester through written exams, but all university courses are given orally. Consequently, the deaf students are able to attend classes only through the mediation of volunteer general sign interpreters, provided by the Social Policy Committee. The interpreting services are offered after the lectures and they are based on either written or recorded class material.

The volunteer interpreters have studied the Greek sign language in courses for hearing people at various private and public institutions, and some of them have obtained the certificate of Greek Sign Language competence, by successfully passing the relevant exams after having completed 450 hours of Greek Sign Language training. There are, however, several issues that need to be addressed: (a) people involved in sign language teaching are not all equally qualified to do $\mathrm{so}^{2}$; (b) the teaching material is usually introduced through foreign sources, and in some private and public schools no material is distributed to the students at all ${ }^{3}$; (c) the lack of terminology ${ }^{4}$ in Greek sign language results in a fundamental defect in the education and training of sign language users and especially volunteer academic interpreters; (d) only about $25 \%$ of those who attend the first level of sign language courses decide to continue up to the fourth level; (e) total immersion in sign language is still impossible, since places where deaf and hearing people can meet and interact effectively are scarce. The issue of the existence of "Deaf Culture" is rarely addressed, and most sign language learners or users do not know exactly what the term entails. This is due to the fact that during sign language class reference is made to the issue by the instructor only by showing a videotape or commenting on his/her personal experiences.

\section{Our Project}

The Short-Term Response to the Needs of the Deaf Students at the Aristotle University of Thessaloniki

In the Social Policy Committee we believe that it is urgent to (a) ensure continuous support for the professionalization of the sign language community interpreting ${ }^{5}$ which takes place in the academic service sector (i.e., the necessary administrative procedures or the health services) and (b) facilitate communication between hearing and deaf participants in order to establish a successful inter- 
linguistic communication in the academic setting ${ }^{6}$ (i.e., (i) the classroom, (ii) the interviews, (iii) the evaluation, (iv) the laboratories and the workshops) (Kassapi \& Efklides, 2004).

\section{The Alternative Support}

(a) The Social Policy Committee and the School of English Studies have organized a short-term training course in sign language interpreting. Despite the fact that training in a post graduate setting will not be possible for two or three more years, we do interdisciplinary research focused on the analysis of a wide range of needs, and we promote collaboration with foreign universities. Starting next year, postgraduate studies abroad will be subsidized by the National Institute for Scholarships.

(b) We have started a program which will enable us to be in contact with people with hearing disabilities, and thus access their needs in the utilization of computers, search for possibilities to meet their requirements, test software and hardware appropriate for their needs and customize the software in order to be useful to the individual deaf students. One example is the use of a piece of software that enables the typing of text through voice. The minimum requirements are a Pentium at $1 \mathrm{GHz}, \mathrm{RAM} 256 \mathrm{MB}$, and $256 \mathrm{MB}$ free space on the hard disk. We have tried it on a Pentium at $2.6 \mathrm{GHz}$ and $256 \mathrm{MB}$ RAM. One must first record the dictated text and then proceed to recognition. This stage requires a lot of RAM space, and as a result a lot of swapping was noticed. Therefore a larger RAM is required to run the program in a reasonable time. We found that the recognition of spoken language is reasonably good. However, the interface was not designed for people with hearing disabilities, so we are currently designing an interface accessible to deaf students with a view to testing its effectiveness with them. (c) There are Distance Learning Systems offered by our University.

(d) There are volunteer groups of undergraduate students who concern themselves with the educational welfare of the deaf.

The long-term response to our type of interpreting needs is dependent on the training of sign language interpreters between spoken and signed Greek. In order to train sign language interpreters for academic purposes, the Social Policy Committee has studied both the educational case of deaf students and the possibility of instituting a post-graduate program for sign interpretation.

By the term "interpreters for academic purposes" we mean hearing professionals who deal with spoken language in education and who are able to manage ${ }^{7}$ their signed production through the typical interpretation procedures ${ }^{8}$ of listening, analyzing, memorizing, and then producing in sublanguages. In Greece there is no official organization of sign-language-interpreter educators which could evaluate the quality of education in signed language interpreting, and officially recognized graduate or post-graduate courses in Greek Sign Language Interpretation have not been instituted yet (Kassapi \& Efklides, 2004).

\section{Training Sign Language Interpreters}

In Aristotle University of Thessaloniki, the training ${ }^{9}$ of sign language interpreters, as mentioned above, is an experimental project by the Social Policy Committee and it is carried out in collaboration with the School of English Studies and the Post-Graduate Program in Translation and Interpretation Studies. We have also seen that this project who initiated because of the awareness that deaf students represent a linguistic minority at our university. The growing number of deaf students has increased the demand for community and conference interpreting between the Greek sign language and the Greek general or special spoken language.

According to research carried out at the Faculty of Philosophy by the Social Policy Committee (Efklides, 2002), 90\% of the students ${ }^{10}$ in the various foreign-language programs at the Aristotle University of Thessaloniki are extremely keen on including the study of Greek sign language as a foreign language in their curriculum. Furthermore, $88 \%$ of these students are willing to take sign language interpreting courses and $63 \%$ of them view sign interpreting as a potential profession. This is due to the fact that the unemployment rate amongst teachers of foreign languages is high, while at the same time there is a growing demand for sign language interpreters. 


\section{The Lack of Terminology in Greek Sign Language: Our Approach}

The lack of Greek sign language terminology makes it imperative for us to define its limits ${ }^{11}$ and to find sources from which to collect its lexicographic data (Snell-Hornby, 1988). One solution would be to institute collaborative projects at an international level aiming at the identification of the local limits of Greek sign language terminology, in order to produce monolingual ${ }^{12}$ and multilingual $^{13}$ term banks. In our view, priority should be given not only to local signs, frequently used by Greek sign language speakers, but also to the activation of direct borrowing from existing foreign term banks $^{14}$ (Wright, 1997 / Efklides, Kassapi \& Polatoglou, 2005).

\section{Discussion}

We still lack material on the processing paradigm ${ }^{15}$ in interpreting, but we are currently working on the strategy paradigm (thinking-aloud protocols, video tapes) and this will be the source of backward inferences on empirically observed phenomena, such as eye fixation and movement. Yet it will be impossible for an interpreter to solve problems in academic sign interpreting unless there is standardization of terminology in an international terminological base. We have confidence in the future initiatives of the International research commission aiming at the production of a multilingual thesaurus of sign terminology, a process in which we are most willing to participate with our data.

\section{NOTES}

We would like to thank Lia Vissa for the French abstract and Margarita Mitsika for the revision of the English translation.

1. Foreign universities have taken significant steps in the area of sign interpretation with respect to interpreters' training courses and research. More specifically: (a) at the $\mathrm{Ca}^{\prime}$ Foscari University in Venice there is a three-year undergraduate course in sign interpretation leading to a diploma; (b) the Center for Deaf Studies at Bristol University in the UK offers a wide range of undergraduate and postgraduate courses in the field of Deaf Studies; (c) the faculty of Humanities at the University of Amsterdam offers PhD projects in the following subjects: the morphology and syntax of verbs in the sign language of the Netherlands, speech development in deaf infants, complex constituents in the sign language of the Netherlands, the structure of African sign languages; (d) the Department of Interpretation at Gallaudet University offers a Master of Arts in Sign Interpretation; (e) the University of Quebec in Montreal offers a program in Sign Interpreting leading to the certificat en interprétation visuelle or a mineure en interprétation visuelle. Very significant research projects are carried out by Le groupe de recherche sur la LSQ et le bilinguisme sourd, such as linguistic description of LSQ aiming at the production of didactic material, research on bilingualism, study of the social mechanisms of deaf culture, and the neurolinguistic study of the acquisition and recall of the mental lexicon in French and LSQ,

2. Some have attended teacher-training courses or have a related Master's Degree, whereas others are simply Greek sign language native speakers.

3. Even at the department for the education of deaf students, in the Pedagogical Institute of Greece, where proposals have been made regarding the general education of deaf students, the material is very poor, consisting of only a few transliterations, as in a glossary for the early grades of elementary school. This material has major drawbacks, such as the lack of representational clarity and the fact that the entries for verbal expressions do not cover the daily routines of the user (Kourbetis \& Efthimiou, 2004).

4. Professionally produced material for student practice is limited (i.e., in a high school for deaf students, we have noticed a number of cds on physics, chemistry and mathematics which were supposed to be produced by the students themselves, but they are not published or are out of print and the only people actually having access to them are the school's students. They were unwilling to explain why the same procedure was not applied to other subjects such as Greek, Classical Greek, History, Psychology or others.

5. Greece, like other European countries, has made no effort to formalize national standards in education and testing for community interpretation. 
6. "Conference interpreting" for academic purposes (in order to facilitate communication between hearing and deaf participants, so that successful inter-linguistic communication is established in the academic setting) requires acquired knowledge in the specific fields of the programs in which deaf students are registered, combined with a relevant conceptual and terminological background.

7. The main difference between a foreign language interpreter and a sign language interpreter is the following: the interpreter and his/her hearing audience can communicate through the booth, whereas it is imperative for the sign language interpreter to have a continuous visual contact with the audience. In other words, the sign language interpreter needs to have a deep knowledge of the triple structure of communication and a great command of paralinguistic and kinetic features, both of the hearing and the deaf community, in order to avoid the centrifugal aspects of communication, such as visual kinesics, visual parts of audible gestures, and the paralinguistic accompaniment of oral production (Poyatos, 2002). Therefore, academic sign interpreters have to: (a) be aware of the deaf culture; (b) master both spoken and signed Greek as working languages for academic purposes; (c) possess specialized supplementary knowledge acquired prior to sign interpreting. That is, they must master a sub-language on a terminological and ontological basis.

8. Interpreters, interpreter educators and interpreter researchers are convinced that (a) interpreting between a signed and a spoken language requires the same expertise as interpreting between two spoken languages and (b) sign language interpreters are top communicators providing a truly professional service (Isham, 1995).

9. In recent years many sign language interpreters have been practitioners in Central and Eastern Europe, as well as in Greece. In Greece accreditation can be received, by private or semi-public organizations, after passing exams. Professional training is also supported by non-state or semi-public organizations, which have made considerable efforts through the years to train not only interpreters but also Greek users of sign as a foreign language (i.e., in Thessaloniki the School for Deaf Students has offered successful courses).

10. $65 \%$ of the teaching staff and $70 \%$ of the administrative personnel are willing to learn Greek sign language.

11. The study for the acquisition and interpretation of terminology in sign language in each program at the Aristotle University of Thessaloniki focuses on two distinct and interrelated levels: (a) the production and collection of Greek sign language terminology in each faculty by the highest-ranking graduates in each program, as it is these graduates who will supply the academic interpreters with the required terminology, based on the established communication patterns among deaf students or between deaf students and their volunteer interpreters (Ladmiral \& Mériaud, 2005). This will enable us to define the students' urgent needs and to study the morphology, syntax and lexicon of the sign language for the proper training of potential interpreters; (b) the acquisition of existing international term banks produced by other universities and authorized institutions.

12. A monolingual term bank could include terms such as the names of educational institutions, qualifications, and roles, or legal terms such as "judicial nomenclature" (Wright, 1997).

13. A multilingual term bank could include scientific concepts, abbreviations, symbols and formulas (Wright, 1997).

14. Such as Banque visuelle de signes de la LSQ by Le groupe de recherche sur la LSQ et le bilinguisme sourd.

15. The potential of psycholinguistic research in translation studies: education in sign language interpretation is also recognized as a field for interdisciplinary research because (a) the signs interpreted are special instances of bilingual communication between spoken and signed language; (b) interpreting constitutes a mental process relying on information processing skills; (c) it activates (i) top-down strategies when it is sense-oriented, with the focus on the function and (ii) bottom-up strategies, with the focus on semi-automatic lexical transfer, when it is sign-oriented (Shlesinger, 1995).

\section{REFERENCES}

EFKLIDES, A. (2002): Spoudes ke zoi ton neon me idikes anages sto panepistimio (Life and study of students with special needs in university), Thessaloniki, Social Policy Committee, p. 70-73.

EFKlides, A., E. KASSAPI, \& H. Polatoglou (2005): “Orologia stin eliniki noimatiki” (Greek Sign Language and Terminology), Greek Language and Terminology V, p. 88-96.

HARRIS, B. (1995): Translation and Interpreting Schools, Language International World Directory, Amsterdam, Benjamins, p. 13, 38, 42, 44, 45, 148, 223.

IsHAM, W. (1995): “On the Relevance of Signed Languages to Research in Interpretation”, Target 7-1, GILE, D. (ed.), p. 135-149. 
KASSAPI, E. \& A. EFKLIDES (2004): What Lies Ahead for Sign Language Post-Graduate Interpreting Courses? Paper presented at the $1^{\text {st }}$ International Conference on the Quality of Life and Psychology, Thessaloniki. Kourbetis, V. \& E. EFTHimiou (2004): Ta prota mou noimata (My first signs), Athina, Kastaniotis. LAdMIRAL, J.-R. \& M. MÉRIAUd (2005): Former des traducteurs: pour qui? Pour quoi?, in BAlliU, C. (ed.): 50e anniversaire Meta, p. 28-35.

Poyatos, F. (2002): Non Verbal Communication Across Disciplines, Amsterdam, Benjamins.

Routledge Encyclopedia of Translation Studies (1998): in BAKER, M. (ed.), London, Routledge, p. 33, 40, 185, 231, 249, 251, 255, 258, 262.

Shlesinger, M. (1995): "Stranger in Paradigms", Target 7-1, Gile, D. (ed.), p. 7-28

SNELl-HornBy, M. (1988): Translation Studies, Amsterdam, Benjamins.

WRiGHT, S. E. (1997): Handbook of Terminology Management, Amsterdam, Benjamins, p. 42-61. 